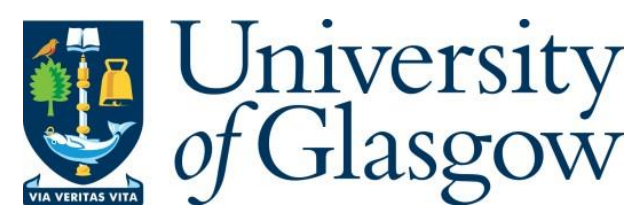

Dorris, L. (2020) Considering resilience models in recovery from pediatric stroke. European Journal of Paediatric Neurology, 25, p. 1.

There may be differences between this version and the published version. You are advised to consult the publisher's version if you wish to cite from it.

$\underline{\text { https://eprints.gla.ac.uk/218748/ }}$

Deposited on: 22 June 2020

Enlighten - Research publications by members of the University of Glasgow https://eprints.gla.ac.uk 


\section{Considering resilience models in recovery from pediatric stroke}

In this issue, Darling et $\mathrm{al}^{1}$ report on a prospective longitudinal study of cognitive, language and motor skills following acute arterial stroke. Importantly, as well as reporting 'static' risk factors associated with poorer cognitive outcomes such as neonatal stroke, large lesions, cortical only lesions, and middle cerebral artery involvement, they found that the majority of children showed 'resilience' in terms of their cognitive outcomes at one-year post-insult. As the authors note, most of the published evidence concerning outcomes after paediatric stroke relates to the description of impairment, often in cross-sectional cohorts presenting in a clinical or neurorehabilitation context. In consequence, findings have been inconsistent across studies both in relation to the proportion of children presenting with long-term functional impairment, and in relation to the influence of static factors such as age at insult or lesion size.

Childhood stroke is defined as an acute cerebrovascular event involving either an arterial ischemic stroke or hemorrhagic stroke and can also be described in relation to age, with neonatal stroke more common (1/4000 births) than later childhood stroke occurring in only 1-10 cases per $100,000^{2}$. In an earlier population-based cohort looking at perinatal arterial ischemic stroke, the Alberta Perinatal Stroke Project ${ }^{3}$ reported that children with bilateral, large vessel perinatal stroke were at high risk of severe cognitive and motor sequelae, and a higher risk of epilepsy than children with unilateral lesions. The issue of timing is important in judging outcomes. Whilst Darling et al report the absence of seizures and older age at stroke predict better cognitive outcomes at one year, sex, comorbid diagnoses, socioeconomic status and parent factors made little contribution. It is unsurprising that family and sociodemographic variables are less potent in moderating outcomes early in the recovery from a severe brain injury when biological mechanisms are more active. In contrast, there is a significant body of research showing that with increasing time since injury these factors increasingly do influence behavioral, educational and mental health outcomes ${ }^{4,5}$.

Resilience has been conceptualised as multidimensional construct encapsulating concepts related to positive patterns of adaptation in the context of adversity. Within a neurorehabilitation context, these constructs reflect both static (e.g. age, lesion, seizures, 
acute neurological complications) and dynamic resilience factors such as socio-economic factors, premorbid developmental and family functioning variables. There has been increasing interest within the child health literature in the related concepts of adversity and resilience, with recognition that risk increases with exposure to multiple risk factors and in the absence of protective mediating resilience factors ${ }^{6}$.

The clinical information imparted to children and families during contact with treating neurologists, neuropsychologists and therapists during post-acute care is important in shaping expectations. Access to good quality evidence around cognitive outcomes is of clear importance in providing balanced and clear information on prognosis. The resilience model reported by Darling et al provides a useful framework for practitioners in the field of paediatric neurology and neurorehabilitation.

Liam Dorris

Paediaric Neurosciences Research Group

Royal Hospital for Children,

Glasgow, Scotland, G51 4TF, UK.

E-mail address: liam.dorris@ggc.scot.nhs.uk

1. Simone Darling S, Anderson V, Mckay M, Monagle P, Greenham M, Cooper A, Hunt R, Hearps S, Gordon A. Cognitive resilience following pediatric stroke: biological and environmental predictors. European Journal of Pediatric Neurology (this edition)

2. Mallick, A.A., et al., Childhood arterial ischaemic stroke incidence, presenting features, and risk factors: A prospective population-based study. The Lancet Neurology, 2014. 13(1): p. 35-43.

3. Mineyko A, Kirton A. Long-Term Outcome After Bilateral Perinatal Arterial Ischemic Stroke. Pediatr Neurol. 2019. pii: S0887-8994(19)30587-9. doi:

10.1016/j.pediatrneurol.2019.07.013

4. Yeates, K. O., Taylor, H. G., Walz, N. C., Stancin, T., \& Wade, S. L. (2010). The family environment as a moderator of psychosocial outcomes following traumatic brain 
injury in young children. Neuropsychology, 24(3), 345356. https://doi.org/10.1037/a0018387

5. Durber CM, Yeates KO, Taylor HG, Walz NC, Stancin T, Wade SL.The family environment predicts long-term academic achievement and classroom behavior following traumatic brain injury in early childhood. Neuropsychology. 2017 Jul;31(5):499-507. doi: 10.1037/neu0000351.

6. Dinkler, L., Lundström, S., Gajwani, R., Lichtenstein, P., Gillberg, C., and Minnis, H. (2017) Maltreatment-associated neurodevelopmental disorders: a co-twin control analysis. J Child Psychol Psychiatry. 58(6) pp. 691-701. doi: 10.1111/jcpp.12682. Epub 2017 Jan 17. 